\title{
Impact of adalimumab on work participation in rheumatoid arthritis: comparison of an open-label extension study and a registry-based control group
}

\author{
M T Halpern, ${ }^{1}$ M A Cifaldi, ${ }^{2}$ T K Kvien ${ }^{3}$
}

${ }^{1}$ Department of Health Policy and Management, Emory University, Atlanta, Georgia, USA; ${ }^{2}$ Global Health Economics and Outcomes Research, Abbott Laboratories, Abbott Park, Illinois, USA; ${ }^{3}$ Department of Rheumatology, Diakonhjemmet Hospital, Oslo, Norway, and Faculty of Medicine, University of Oslo, Oslo, Norway

\section{Correspondence to:}

Dr M Halpern, Emory University, Department of Health Policy and Management, 1599 Clifton

Road, Atlanta, Georgia 30329,

USA; mthalpe@emory.edu

Accepted 17 September 2008

Published Online First

1 October 2008

\begin{abstract}
Background and objectives: Rheumatoid arthritis (RA) causes considerable disability and often results in loss of work capacity and productivity. This study evaluated the impact of adalimumab, a tumour necrosis factor antagonist with demonstrated efficacy in RA, on longterm employment.
\end{abstract}

Methods: Data from an open-label extension study (DE033) of 486 RA patients receiving adalimumab monotherapy who previously did not respond to at least one disease-modifying antirheumatic drug (DMARD) and had baseline work status information were compared with data from 747 RA patients receiving DMARD treatment in a Norway-based longitudinal registry. Primary outcomes included the time patients continued working at least part time and the likelihood of stopping work. Secondary outcomes included American College of Rheumatology (ACR) and European League Against Rheumatism (EULAR) responses and disease remission. Outcomes were compared 6, 12 and 24 months after enrolment.

Results: During a 24-month period, the 158 patients who received adalimumab and were working at baseline worked 7.32 months longer $(95 \% \mathrm{Cl} 4.8$ to 9.1$)$ than did the 180 patients treated with DMARDs, controlling for differences in baseline characteristics. Regardless of baseline work status, patients receiving adalimumab worked 2.0 months longer (95\% Cl 1.3 to 2.6 ) and were significantly less likely to stop working than those receiving DMARDs (HR $0.36(95 \% \mathrm{Cl}-0.30$ to 0.42$)$ for all patients and 0.36 (95\% Cl 0.15 to 0.85$)$ for patients working at baseline, respectively). The patients who received adalimumab were also considerably more likely to achieve ACR responses and disease remission than DMARD-treated patients. Patients who achieved EULAR good response and remission were less likely to stop working, but this relationship was only seen in patients receiving DMARDs

Conclusions: Patients with RA who received adalimumab experienced considerably longer periods of work and continuous employment, and greater rates of clinical responses, than patients receiving DMARDs. The mechanism by which adalimumab decreases likelihood of stopping work seems to be different from that of DMARD treatment and independent of clinical responses.

Rheumatoid arthritis (RA), a chronic inflammatory disease of unknown aetiology affecting $0.5 \%$ to $1.0 \%$ of the adult population, ${ }^{1-3}$ has a negative impact on the physical, psychological and social health of patients ${ }^{4}$ and may cause considerable disability. ${ }^{5-9}$ The inability to perform activities of daily living, impairment in quality of life and loss of work capacity eventually lead to increased direct and, to a larger extent, indirect costs. ${ }^{10-16}$ Indirect costs are consistently greater than direct costs and can be attributed to reduced functionality and attendance at work for those patients still employed, ${ }^{17-20}$ early retirement due to RA and sick leave by employed patients. ${ }^{21}$ In one study, the largest components of annual workplace cost attributable to arthritis were decreased productivity (41\%) and wages lost from stopping work or changing jobs $(37 \%){ }^{22}$

There is no cure for RA, and treatments have been aimed at providing symptomatic relief, slowing joint damage and preventing functional disability. Although aggressive management with standard therapies has provided symptomatic relief for many patients, tumour necrosis factor (TNF) antagonists have further improved the management of $\mathrm{RA}^{2324}$ through marked reductions in the manifestations of RA, improvements in function, slowed radiographic progression and improvements in patients' quality of life. ${ }^{25-28}$ However, data on whether these treatments affect workrelated productivity are limited. ${ }^{29}$ Data are also needed to determine whether response to treatment with TNF antagonists has consequences for work capacity.

A cross-sectional analysis of randomised controlled trials of etanercept showed greater employment rates among patients treated with this TNF antagonist. $^{30}$ However, longitudinal studies can examine the effects of illness over time and may provide a more robust picture of the impacts of comparative therapies than can cross-sectional studies. The objective of this study was to evaluate the long-term impact of therapy with the TNF antagonist adalimumab on employment among patients with RA. Data from RA patients who participated in a recent European open-label extension study of adalimumab were compared with data from patients enrolled in a Norwegian longitudinal observational study involving treatment with conventional disease-modifying antirheumatic drugs (DMARDs).

\section{METHODS}

\section{Study populations}

We obtained the data for these analyses from two sources. Information on patients receiving adalimumab therapy was obtained from an open-label extension study conducted by Abbott Laboratories (study DE033). The extension study enrolled patients who had completed one of six adalimumab clinical trials. ${ }^{31}$ These trials involved patients from Europe, Australia and Canada who had not online under the BMJ Journals unlocked scheme, see http:// ard.bmj.com/info/unlocked.dtl 
responded to treatment with at least one DMARD previously. Patients entering the extension study may have received placebo, low-dose adalimumab or standard-dose adalimumab in the previous clinical trial. All patients participating in DE033 received adalimumab $40 \mathrm{mg}$ every other week. All of the previous six adalimumab clinical trials leading to DE033 had similar inclusion criteria. In general, patients enrolled had:

- moderate to severe RA for a mean of approximately 12 years;

- on average, been treated with approximately four DMARDs previously;

- a mean 28-joint Disease Activity Score (DAS28) of approximately 5.2 .

Dropout rates from the six prior adalimumab clinical studies were examined to ensure that a large number of non-responders had not dropped out before entry into this open-label study. Study discontinuations resulting from adverse events occurred in $3 \%(22 / 816)$ of patients and those owing to lack of efficacy occurred in $11 \%(90 / 816)$ of patients initially receiving adalimumab in the preceding studies. ${ }^{32-37}$

No control or comparison group was included in the DE033 open-label extension study. To evaluate longitudinal differences among patients receiving adalimumab in the current study, we compared the DE033 population with patients from the Norway-based longitudinal registry (NOR-DMARD) of patients with RA and other inflammatory arthropathies being treated with DMARDs. ${ }^{38}$ Patients with RA who were prescribed methotrexate or leflunomide (alone or in combination with other DMARDs) after previously not responding to least one DMARD regimen (consistent with the inclusion criteria for DE033) were eligible for this study. Other inclusion criteria for DE033 and NOR-DMARD patients were comparable. Data from each group of patients were included for up to 2 years following study enrolment. However, patients in the NORDMARD study with less than 2 years of follow-up data (owing to either study discontinuation or study enrolment less than 2 years prior to this analysis) were also included in analyses for time points prior to 2 years (baseline, 6 months and 12 months).

\section{Outcome measures}

The primary outcome measures for this study were the time patients remained at work and the likelihood of stopping work. For these outcome measures, individuals who were working at least part time at baseline (ie, DE033 or NOR-DMARD enrolment) were assessed at 6,12 and 24 months to determine whether they were still working at least part time. Owing to small numbers, no differentiation was made between those working full time and those working part time. As these data were collected only at 6, 12 and 24 months, analyses used the midpoint of each interval for duration of time worked. The same assumption was applied to patients from the DE033 study and the NOR-DMARD registry.

We also included three secondary outcome measures in this study:

- the likelihood of achieving American College of Rheumatology (ACR) responses (ACR20, ACR50 and ACR70) at 6, 12 and 24 months following enrolment in DE033 or NOR-DMARD;

- the likelihood of experiencing a good response according to the European League Against Rheumatism (EULAR) criteria;

- the likelihood of experiencing disease remission as measured by the DAS28.

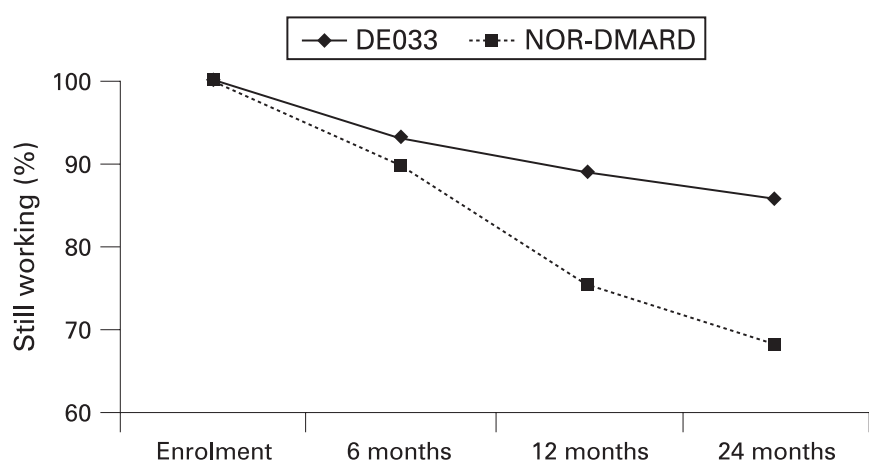

Figure 1 Percentage of study participants working at enrolment who have continued working over time. NOR-DMARD, patients receiving diseasemodifying antirheumatic drugs from Norway-based longitudinal registry.

Calculations of ACR outcome measures have been described elsewhere. ${ }^{39}$ For this analysis, numbers of swollen and tender joints were based on counts of 28 joints, as only 28 -joint counts were available in the NOR-DMARD data set. Patient-rated assessment of pain and physician-rated assessments of global disease activity were evaluated using 100-point visual analogue scales.

The DAS28 was calculated (based on erythrocyte sedimentation rate) at each available time point (baseline and 6, 12 and 24 months). ${ }^{40}$ A EULAR response was calculated based on a DAS28 score $\leqslant 3.2$ and a decrease in DAS28 from baseline $>1.2 .{ }^{41}$ Consistent with previous analyses, a DAS28 < 2.6 was used to identify patients in disease remission.

\section{Analyses}

We compared baseline clinical, demographic and working characteristics for DE033 and NOR-DMARD patients using $\chi^{2}$ tests (for dichotomous variables) and Student $t$ tests (for continuous variables). Baseline characteristics with statistically significant differences were then controlled for in subsequent multivariate regressions. The patients' average monthly wage was used to calculate work loss, so the financial implication was from a patient perspective rather than an employer perspective.

For the analysis of available work data, we assumed that patients who stopped working did not return to work at a later time point. Therefore, for the analysis of the likelihood of stopping work at 6, 12 and 24 months, patients who had previously stopped working before one of these time points were included in all subsequent analyses, even if they had missing work data or incomplete study follow-up. Patients who were working at one time point and did not have work data for subsequent time points were excluded from subsequent analyses.

We used multivariate ordinary least square regression to compare duration worked (ie, time patients remained at work) for patients receiving adalimumab versus DMARDs, controlling for significant differences in baseline characteristics. Separate regression analyses were performed for the entire study population (which included individuals who were not working at study entry) and the subset of the population working at baseline. Collinearity diagnostics were performed for regression of both the entire study population and the population working at baseline. Substantial collinearity was present if the largest condition index was greater than 100 .

In addition, multivariate proportional hazards $(\mathrm{PH})$ regression was used to evaluate the likelihood of stopping work while 
controlling for duration of study enrolment, dropout rates, and baseline clinical differences. Two separate $\mathrm{PH}$ analyses were performed: one involving all study patients, whether or not they were working at baseline, and a second that included only individuals who were working at baseline. For these analyses, stopping work was an event; individuals who had been enrolled in the study for less than 2 years and who were working at their last study visit, as well as individuals who were still working at 2 years, were considered censored. Diagnostics run for both the overall study population and the population working at baseline indicated that the $\mathrm{PH}$ assumption was valid.

Multivariate $\mathrm{PH}$ regressions were also used to compare the likelihood (hazard ratio) of achieving ACR outcomes (ACR20, ACR50 or ACR70), a good EULAR response and disease remission based on DAS28 scores over the period of available follow-up data while controlling for the clinical factors that differed between the groups at baseline. In this $\mathrm{PH}$ regression, achievement of these clinical outcomes was an event, and the time to the first such event was used in the analysis. Patients who did not achieve a particular outcome within their followup period were considered censored for that outcome.

We also performed multivariate $\mathrm{PH}$ regressions across treatment groups to examine whether achievement of clinical response influenced the likelihood of stopping work. All analyses were conducted using SAS V.9.1. Confidence intervals for the differences in the means are provided. No interpolation of missing data was performed.

\section{RESULTS}

Most of the 505 patients in DE033 (69\%) were from northern Europe (Belgium, the Netherlands, Great Britain, France, Germany, Austria and Switzerland). An additional 10\% of patients were from southern Europe (Spain and Italy), and the remaining 21\% were from Australia and Canada. Of the 505 patients enrolled in DE033, 68 had received placebo in the preceding clinical studies; the remainder continued adalimumab therapy in this open-label extension. Information on work status at baseline (ie, study entry) was available for 486 DE033 patients and 747 NOR-DMARD patients, and only these populations were included in the study analyses.

To appropriately compare outcomes between DE033 patients and NOR-DMARD patients, we first compared baseline characteristics for all patients and for the subset of patients who were working at baseline, $n=158$ and $n=180$, respectively; table 1). In the overall population, there were no significant differences in the sex distribution or mean duration of RA, but significant differences were observed in demographic and several disease activity variables. The magnitude in the difference for clinical measures (acute-phase reactants and joint counts) was relatively small, whereas the differences in responses to subjective assessments (visual analogue scale measures) were proportionally larger. This difference may be a reflection of DE033 being a continuation of clinical trials that participating patients had already completed, whereas the NOR-DMARD patients were just beginning a new study experience. However, we included all of the statistically significant baseline factors in the subsequent multivariate regressions. When baseline characteristics were examined for those patients working at baseline, age, disease duration, Creactive protein concentration and erythrocyte sedimentation rate were lower for patients working at baseline than for the entire cohort.

Figure 1 shows the percentage of study participants working at enrolment who continued working over time. At 12 months, 179 patients were working (117 in the adalimumab group and 62 in the DMARD group), whereas 144 patients (108 and 36, respectively) were working at 24 months. A significantly greater percentage of patients in the adalimumab group than in the DMARD group were working at 12 months (mean difference $13.8 \%$; $95 \%$ CI $3.4 \%$ to $24.2 \%$ ) and at 24 months (mean difference $17.6 \%$, 95\% CI $4.6 \%$ to $30.7 \%$ ) ( $p<0.05)$. Multivariate linear regression analyses were performed to evaluate the duration of work while controlling for baseline differences between the two populations. Among all patients (those working and those not working at enrolment), those receiving adalimumab worked for 0.17 years (approximately 9 weeks) longer than those receiving DMARDs over the study period of

Table 1 Baseline characteristics of DE033 and NOR-DMARD patients

\begin{tabular}{|c|c|c|c|c|c|c|}
\hline \multirow[b]{3}{*}{ Characteristic } & \multicolumn{3}{|l|}{ All patients } & \multicolumn{3}{|c|}{ Patients working at baseline } \\
\hline & \multicolumn{2}{|l|}{ Mean $(95 \% \mathrm{CI})$} & \multirow[b]{2}{*}{$95 \% \mathrm{Cl}^{*}$} & \multicolumn{2}{|l|}{ Mean $(95 \% \mathrm{CI})$} & \multirow[b]{2}{*}{$95 \% \mathrm{Cl}^{*}$} \\
\hline & DE033 ( $n=486)$ & $\begin{array}{l}\text { NOR-DMARD } \\
(\mathrm{n}=747)\end{array}$ & & DE033 (n = 158) & NOR-DMARD $(n=180)$ & \\
\hline Disease duration (years) & $12.3(11.6$ to 13.0$)$ & $13.0(12.3$ to 13.6$)$ & -1.7 to 0.4 & $10.5(9.4$ to 11.6$)$ & 10.7 (9.5 to 11.9$)$ & -1.8 to 1.5 \\
\hline Women (\%) & 78.2 (74.5 to 81.9$)$ & $74.3(71.2$ to 77.4$)$ & -8.8 to 10.0 & $69.0(61.7$ to 76.3$)$ & $68.3(61.5$ to 75.2$)$ & -9.3 to 10.6 \\
\hline Working at baseline (\%) & 32.5 (28.3 to 36.7$)$ & 24.1 (21.0 to 27.2$)$ & 3.3 to 13.5 & - & - & - \\
\hline Age (years) & 53.7 (52.6 to 54.8$)$ & $57.0(56.1$ to 58.0$)$ & -4.8 to -1.9 & 45.3 (43.7 to 46.9 ) & 48.1 (46.7 to 49.5$)$ & -4.9 to -0.7 \\
\hline C-reactive protein (mg/L) & 195 (172 to 218$)$ & 245 (226 to 263$)$ & -79 to -21 & 190 (150 to 229$)$ & 187 (157 to 228$)$ & -47 to 52 \\
\hline $\begin{array}{l}\text { Erythrocyte sedimentation rate } \\
(\mathrm{mm} / \mathrm{h})\end{array}$ & $31.4(29.4$ to 33.5$)$ & 28.7 (27.1 to 30.4 ) & 0.1 to 5.3 & 27.4 (24.1 to 30.7$)$ & $20.3(17.7$ to 23.0$)$ & 2.9 to 11.2 \\
\hline Swollen joint count (28 joints) & $6.1(5.6$ to 6.6$)$ & $8.1(7.7$ to 8.5$)$ & -2.7 to -1.4 & $6.6(5.6$ to 7.5$)$ & $7.4(6.6$ to 8.2$)$ & -2.1 to 0.4 \\
\hline Tender joint count (28 joints) & $7.0(6.4$ to 7.7$)$ & $8.2(7.7$ to 8.7$)$ & -2.0 to -0.4 & $7.0(5.9$ to 8.1$)$ & $7.0(6.1$ to 7.9$)$ & -1.4 to 1.4 \\
\hline DAS28 & 4.2 (4.0 to 4.3 ) & $4.9(4.8$ to 5.0$)$ & -0.9 to -0.6 & $4.2(3.9$ to 4.4$)$ & $4.6(4.4$ to 4.8$)$ & -0.7 to -0.2 \\
\hline $\begin{array}{l}\text { Patient-rated joint pain } \\
\text { (0-100 VAS) }\end{array}$ & 33.0 (30.9 to 35.2$)$ & $50.9(49.3$ to 52.5$)$ & -20.5 to -15.3 & $31.4(27.7$ to 35.2$)$ & 44.9 (41.7 to 48.2$)$ & -18.4 to -8.6 \\
\hline $\begin{array}{l}\text { Patient-rated global disease } \\
\text { activity (0-100 VAS) }\end{array}$ & $27.3(25.3$ to 29.2$)$ & 42.5 (41.2 to 43.7$)$ & -17.4 to -13.0 & $32.2(28.5$ to 35.8$)$ & 49.4 (46.0 to 52.8 ) & -22.2 to -12.2 \\
\hline $\begin{array}{l}\text { Physician-rated global disease } \\
\text { activity (0-100 VAS) }\end{array}$ & $33.3(31.2$ to 35.4$)$ & $54.9(53.2$ to 56.5$)$ & -24.2 to -18.9 & $26.8(23.5$ to 30.1$)$ & 39.8 (37.3 to 42.2 ) & -17.0 to -9.0 \\
\hline
\end{tabular}

*Confidence intervals refer to the difference between the DE033 and NOR-DMARD groups within the category "All patients" or "Patients working at baseline". DAS28, 28-joint Disease Activity Score; NOR-DMARD, patients receiving disease-modifying antirheumatic drugs from Norway-based longitudinal registry; VAS, visual analogue scale. 
2 years (95\% CI 0.11 to 0.22 ; table 2 ). Among patients working at least part time at baseline (180 (24.1\%) of the DMARD group and $158(32.5 \%)$ of the adalimumab group), patients receiving adalimumab worked for 0.61 years (approximately 32 weeks) longer than did the patients receiving DMARDs over the 2 study years ( $95 \%$ CI 0.42 to 0.79 ; table 2 ). We did not observe substantial collinearity among the independent variables for these regressions. Of the 1233 patients enrolled in the study, 895 patients were not working at baseline. Of these, 17 were working at 6 months (7 adalimumab-treated and 10 DMARDtreated patients), 19 were working at 12 months ( 8 adalimumab-treated and 11 DMARD-treated patients) and 15 were working at 24 months (6 adalimumab-treated and 9 DMARDtreated patients). Therefore, an overwhelming majority (>95\%) of patients who stopped working did not return to work.

To further control for baseline differences between the two study populations and available study enrolment over the 3year period, we performed multivariate $\mathrm{PH}$ regression. Patients in the adalimumab group were significantly less likely to stop working than patients in the DMARD group (table 2). Results were consistent for both the overall study population and for the subpopulation of patients who were working at study enrolment. Among DE033 patients, we also evaluated whether treatment allocation (adalimumab or placebo) in the six clinical trials that preceded DE033 influenced the likelihood of stopping work. Using the multivariate $\mathrm{PH}$ regression presented in table 2, treatment arm allocation in the previous clinical trials was not significantly associated with likelihood of stopping work (data not shown).

Table 3 shows the results of $\mathrm{PH}$ regression analyses for the secondary outcome variables. Patients treated with adalimumab were significantly more likely to achieve ACR20, ACR50, ACR70, a good EULAR response and DAS28 remission (table 3) than were patients receiving DMARDs. Among the DE033 patients, we also evaluated whether treatment allocation (adalimumab or placebo) in the preceding clinical trials influenced likelihood of achieving clinical responses. In contrast to the results of the similar subanalysis performed to evaluate stopping work, treatment allocation was significantly associated with likelihood of achieving responses. Patients who received placebo in clinical trials that preceded DE033, and thus received adalimumab for the first time in $\mathrm{DE} 033$ (ie, they were adalimumab-naïve when they entered DE033), were more likely

Table 2 Analysis of the impact of adalimumab compared with diseasemodifying antirheumatic drug (DMARD) treatment on work outcomes

Adalimumab vs DMARD-treated

patients $(95 \% \mathrm{Cl})$

\begin{tabular}{ll}
\hline Additional duration worked (years) & \\
All patients & $0.17(0.11$ to 0.22$)$ \\
Patients working at baseline & $0.61(0.42$ to 0.79$)$ \\
Hazard ratio for stopping work & \\
All patients & $0.36(0.30$ to 0.42$)$ \\
Patients working at baseline & $0.36(0.15$ to 0.85$)$
\end{tabular}

*Duration worked for patients receiving adalimumab versus DMARDs from multivariate ordinary least-square regression controlling for percentage working at baseline (for analysis of all patients only) and baseline age, erythrocyte sedimentation rate, C-reactive protein concentration, number of swollen and tender joints, 28-joint Disease Activity Score, and joint pain, patient-rated global and physician-rated global assessment visual analogue scale scores.

† Hazard ratio for patients receiving adalimumab compared with DMARDs from proportional hazards regression controlling for time to event (stopping work), duration of study enrolment, percentage working at baseline (for analysis of all patients only), and baseline age, erythrocyte sedimentation rate, C-reactive protein, number of swollen and tender joints, 28-joint Disease Activity Score, and joint pain, patient-rated global and physician-rated global assessment visual analogue scale scores.
Table 3 Proportional hazards analysis of the impact of adalimumab versus disease-modifying antirheumatic drug therapy on American College of Rheumatology (ACR) response, European League Against Rheumatism (EULAR) good response and 28-joint Disease Activity Score (DAS28) remission*

\begin{tabular}{ll}
\hline Outcome & $\begin{array}{l}\text { Hazard ratio among DE033 } \\
\text { patients (95\% CI) }\end{array}$ \\
\hline Achieve ACR20 & $1.890(1.477$ to 2.419$)$ \\
Achieve ACR50 & $1.949(1.353$ to 2.806$)$ \\
Achieve ACR70 & $2.088(1.137$ to 3.836$)$ \\
Achieve EULAR good response & $1.625(1.188$ to 2.224$)$ \\
Achieve disease remission-all patients & $1.826(1.323$ to 2.520$)$ \\
Achieve disease remission-patients without remission & $2.511(1.721$ to 3.662$)$ \\
at study enrolment & \\
\hline
\end{tabular}

*From proportional hazards regressions controlling for time to event (ACR response or disease remission), duration of study enrolment, percentage working at baseline (for analysis of all patients only) and baseline age, erythrocyte sedimentation rate, Creactive protein concentration, number of swollen and tender joints, DAS28, and joint pain, patient-rated global and physician-rated global assessment visual analogue scale scores.

to achieve ACR20 ( $p=0.047)$, ACR50 ( $p=0.03)$ and ACR70 $(p=0.006)$ responses than were patients who received adalimumab before entering DE033 (data not shown). However, the treatment arm (adalimumab or placebo) in clinical trials before DE033 was not significantly associated with achieving a EULAR good response or with experiencing disease remission (either among all patients or among the subgroup of DE033 patients without disease remission at study enrolment).

Table 4 presents multivariate $\mathrm{PH}$ regression analysis results evaluating the relationship between the primary and secondary study outcomes-ie, stopping work and achieving clinical responses, for the entire study population (combining adalimumab and DMARD groups). Patients who achieved ACR outcomes at each of the three study time points were less likely to stop working. This relationship was observed most strongly for patients achieving the ACR20 and ACR50 outcomes. Similar associations were also observed for good response to EULAR criteria and DAS28 remission (table 4).

Table 4 also presents separate analyses evaluating the relationship between stopping work and achieving clinical responses for adalimumab and DMARD patients. Substantially different results were observed for the two populations. Among DMARD patients, a significant relationship was observed between achieving a clinical response and continuing to work. In contrast, among adalimumab patients, the relationship between achieving a clinical response and likelihood of continuing work was not statistically significant for any of the clinical responses. This suggests that the mechanism by which adalimumab leads to decreased rates of stopping work is independent of the observed increased rates of achieving clinical outcomes.

\section{DISCUSSION}

Our study has two main findings. First, patients with RA receiving adalimumab were considerably more likely to continue working. Patients in this study who were receiving adalimumab worked for a longer duration of the 2-year study period than did patients receiving DMARDs (fig 1, table 2). These patients also were more likely to achieve a clinical response (such as ACR outcomes or disease remission, table 3). Second, whereas achievement of clinical response (as measured by the three secondary outcomes) was generally associated with greater likelihood of continuing to work among DMARD patients, this was not the case for adalimumab patients 
Table 4 Impact of American College of Rheumatology (ACR) and disease remission status on stopping work*

\begin{tabular}{|c|c|c|c|}
\hline & \multicolumn{3}{|l|}{ Hazard ratio $(95 \% \mathrm{Cl})$} \\
\hline & $\begin{array}{l}\text { For stopping work } \\
\text { based on achieving } \\
\text { ACR outcomes }\end{array}$ & $\begin{array}{l}\text { For adalimumab } \\
\text { patients }\end{array}$ & For DMARD patients \\
\hline \multicolumn{4}{|l|}{ ACR outcome achieved at 6 months } \\
\hline $\begin{array}{l}\text { ACR20 } \\
\text { ( } n=67 \text { adalimumab, } n=130 \text { comparison) }\end{array}$ & $0.555(0.457$ to 0.674$)$ & $1.011(0.722$ to 1.417$)$ & $0.476(0.375$ to 0.604$)$ \\
\hline $\begin{array}{l}\text { ACR50 } \\
\text { ( } \mathrm{n}=44 \text { adalimumab, } \mathrm{n}=28 \text { comparison) }\end{array}$ & $0.685(0.506$ to 0.929$)$ & $0.894(0.523$ to 1.526$)$ & 0.619 (0.428 to 0.896$)$ \\
\hline $\begin{array}{l}\text { ACR70 } \\
\text { ( } \mathrm{n}=5 \text { adalimumab, } \mathrm{n}=12 \text { comparison) }\end{array}$ & $0.628(0.344$ to 1.147$)$ & 0.447 (0.061 to 3.253$)$ & $0.647(0.343$ to 1.220$)$ \\
\hline \multicolumn{4}{|l|}{ ACR outcome achieved at 12 months } \\
\hline $\begin{array}{l}\text { ACR20 } \\
\text { ( } \mathrm{n}=91 \text { adalimumab, } \mathrm{n}=91 \text { comparison) }\end{array}$ & $0.603(0.493$ to 0.737$)$ & $0.993(0.727$ to 1.356$)$ & $0.481(0.367$ to 0.630$)$ \\
\hline $\begin{array}{l}\text { ACR50 } \\
\text { ( } \mathrm{n}=36 \text { adalimumab, } \mathrm{n}=37 \text { comparison) }\end{array}$ & $0.639(0.474$ to 0.862$)$ & 0.985 (0.619 to 1.568$)$ & 0.539 (0.364 to 0.798$)$ \\
\hline $\begin{array}{l}\text { ACR70 } \\
\text { ( } \mathrm{n}=9 \text { adalimumab, } \mathrm{n}=12 \text { comparison) }\end{array}$ & $0.521(0.291$ to 0.931$)$ & $0.793(0.195$ to 3.226$)$ & $0.530(0.279$ to 1.004$)$ \\
\hline \multicolumn{4}{|l|}{ ACR outcome achieved at 24 months } \\
\hline $\begin{array}{l}\text { ACR20 } \\
\text { ( } \mathrm{n}=105 \text { adalimumab, } \mathrm{n}=62 \text { comparison) }\end{array}$ & $0.514(0.418$ to 0.633$)$ & 1.011 (0.753 to 1.359$)$ & $0.345(0.251$ to 0.475$)$ \\
\hline $\begin{array}{l}\text { ACR50 } \\
\text { ( } \mathrm{n}=50 \text { adalimumab, } \mathrm{n}=25 \text { comparison) }\end{array}$ & $0.572(0.422$ to 0.776$)$ & $1.050(0.695$ to 1.588$)$ & 0.395 (0.247 to 0.632$)$ \\
\hline $\begin{array}{l}\text { ACR70 } \\
\text { ( } \mathrm{n}=20 \text { adalimumab, } \mathrm{n}=10 \text { comparison) }\end{array}$ & $0.588(0.367$ to 0.943$)$ & $1.052(0.579$ to 1.912$)$ & $0.351(0.155$ to 0.795$)$ \\
\hline \multicolumn{4}{|l|}{ Impacts based on DAS28 scores } \\
\hline $\begin{array}{l}\text { EULAR response } \\
\text { ( } \mathrm{n}=97 \text { adalimumab, } \mathrm{n}=118 \text { comparison) }\end{array}$ & 0.572 (0.475 to 0.688$)$ & $1.001(0.753$ to 1.331$)$ & 0.452 (0.354 to 0.578$)$ \\
\hline $\begin{array}{l}\text { Disease remission } \\
\text { ( } \mathrm{n}=165 \text { adalimumab, } \mathrm{n}=85 \text { comparison) }\end{array}$ & $0.669(0.551$ to 0.812$)$ & $1.007(0.753$ to 1.345$)$ & $0.524(0.391$ to 0.702$)$ \\
\hline
\end{tabular}

(table 4). The increased likelihood of continuing work was independent of achieving clinical responses among the patients receiving adalimumab.

The second finding is particularly exciting. It suggests that although the effect of DMARDs on continued working is related to improved clinical responses, the greater effect of adalimumab on continuing work involves processes independent of improved clinical responses (which were also significantly associated with adalimumab treatment). Although the mechanism of action of adalimumab and other anti-TNF agents is not completely understood, it is clear that the biological effects of these agents are different from those of DMARDs. For example, anti-TNF agents have been shown to stimulate production of new autoantibodies (eg, antinuclear antibodies) but reduce production of serum rheumatoid factor and anticyclic citrullinated peptide antibodies. ${ }^{42}$ In addition, adalimumab and certain other anti-TNF agents have been shown to produce complement-dependent lysis and antibody-dependent cellular cytotoxicity and to reduce the numbers of infiltrating synovial granulocyte. ${ }^{43}$ Clinical studies also support differences in the process by which adalimumab and DMARDs can lead to increased duration of working. Anti-TNF agents can produce substantial slowing of radiographic damage compared with DMARD therapy, ${ }^{44}$ and adalimumab has been shown to markedly slow radiographic progression. ${ }^{45}$ Slowed radiographic progression has been correlated with clinical and work findings, in that a recently published longitudinal study showed that radiographic changes and disease activity independently affected physical function among RA patients. ${ }^{46}$ Increased radiographic joint damage and lower Health Assessment Questionnaire (HAQ) scores were also independently associated with work status. ${ }^{23}$ Further, studies in individuals treated with adalimumab have indicated that, although baseline total Sharpe score (TSS) was associated with change in employment status, baseline DAS28 was not. ${ }^{47}$ The present study expands this previous work, and suggests further differentiation in the effects of adalimumab and DMARDs in the treatment of RA.

This study also presents a notable method for evaluating the impact of a treatment when no control group is present. Although the gold standard for clinical trials involves randomising patients to experimental and control groups, such randomisation is not always feasible. In the case of DE033, patients were already receiving adalimumab and could not be randomised to another treatment group. In scenarios where randomisation is not possible or practical, use of separate control groups is a well-established technique. Separate control groups have been used for clinical studies in a diverse range of therapeutic areas. ${ }^{48-51}$ A separate control group was used in a study of RA that evaluated the impact of etanercept on employment. ${ }^{30}$ Randomised controlled trials of RA medications may overestimate patient outcomes. ${ }^{52}$ Thus, our use of two naturalistic, non-randomised studies to evaluate treatment 
differences may provide results that are more generalisable to typical clinical practice.

The present study has a number of similarities to that of Yelin et $a l,{ }^{30}$ which focused on employment outcomes among patients with RA who had received etanercept in a clinical trial. Outcomes for these patients were compared with outcomes for patients in an observational study not receiving etanercept. Multivariate regression analysis was used to control for baseline patient characteristics in evaluating differences in rate of employment between the two populations. Yelin et al had more detailed information on hours worked per week and were able to project differences in average hours per week, but the study involved a smaller population of patients (total of 497 in both groups), and all patients were enrolled at one institution. The present study results are similar to those of Yelin et al and help generalise these methods by including a larger study population, as well as patients recruited from multiple international treatment centres.

A number of other studies have performed related analyses. van der Heijde et $a^{153}$ reported decreased work limitations and increased productivity among patients with ankylosing spondylitis treated with infliximab. However, Smolen et a ${ }^{54}$ reported no difference in employment rates between patients with RA treated with infliximab plus methotrexate versus those treated with methotrexate alone. Puolakka et a ${ }^{55}$ found decreased rates of work disability among patients with RA treated with combination DMARD therapy versus those receiving a single DMARD. Puolakka et $a^{156}$ also found that global assessments of RA severity and HAQ scores were important predictors of productivity loss and work disability among patients with RA. Kavanaugh et $a^{23}$ also found an important association between functional status or radiographic joint damage and employment status.

Beyond the use of a separate control group, this study has other limitations. There were significant differences between the adalimumab and DMARD populations in a number of baseline characteristics, which were addressed by performing multivariate regression analyses. However, there are probably other differences between the populations that were not observed and thus could not be controlled for using this technique, such as differences in eligibility for work disability and pensions in different country. One study found that work disability among early RA patients was 2.6-fold greater in Finland than in the USA. ${ }^{57}$ However, a recent report ${ }^{29}$ indicated that the achievement of work disability in RA was similar between multiple countries. Thus, because our population was more similar to the latter study than an early RA population, we believe this difference is unlikely to substantially affect the findings of the present study. The patients in the NORDMARD group were new to methotrexate or leflunomide after failing to respond to at least one DMARD treatment, whereas a percentage of patients in the DE033 study previously might have experienced a positive response with adalimumab.

In addition, duration of follow-up during the 2-year study period was variable among the DMARD patients. This variation may affect outcomes over time, as patients with greater illness or functional limitations might be more likely to discontinue participation in the DMARD registry. However, discontinuation by these patients would leave a DMARD comparison group with less illness or greater functional ability, thus potentially biasing results against the adalimumab population. Further, by using $\mathrm{PH}$ analysis, we controlled for the duration of study enrolment on both work and secondary clinical response outcomes.
Another important difference between the groups was the manner in which they enrolled in the respective studies. The DMARD patients enrolled in a registry and included individuals with a range of disease durations, prior treatments and disease severity. In contrast, the adalimumab patients had all been participants in adalimumab clinical trials; these patients had not responded to previous RA treatment, and had at least a minimum level of clinical symptoms and functional impairment. By restricting the DMARD patients to those in whom treatment with at least one previous DMARD had failed, we hoped to identify a population similar to the adalimumab patients. However, at baseline, the DMARD patients had (on average) more functional impairment and greater severity of clinical symptoms that did the adalimumab patients. This may reflect that the adalimumab patients were part of an open-label extension study involving this medication. As such, they had all received adalimumab (standard or low dose) or placebo in double-blind, placebo controlled studies and may have received clinical benefit from these treatments. Even patients with RA receiving placebo in clinical trials may experience clinical improvement. ${ }^{58}$ Thus, patients who began the open-label study may have been successfully treated with adalimumab and those who had an unsatisfactory experience may have dropped out prior to the open-label extension, whereas the DMARD-treated patients may not have been successfully treated at enrolment. The evaluation of changes over time may thus bias the present study against the adalimumab patients. As they had already been successfully treated, there was less likelihood of showing subsequent improvement over time, such as changes in ACR or EULAR response criteria. Nonetheless, the patients receiving adalimumab showed significant improvements in outcomes compared with those receiving DMARDs (table 3).

We chose to compare patients in the NOR-DMARD registry with the DE033 study because data collection was similar between these studies. In both studies, patients used self-report questionnaires. In the DE033 study, patients were asked about their working status: whether they were employed, the number of days per week worked, the hours worked per day; whether they were self-employed, homemakers, pensioner/retirees, unemployed, students, or other; and whether they missed work because of their RA within the past 6 months and how many days of work had been missed. NOR-DMARD patients were asked about their occupation, whether they worked full time or part time, were on sick leave, crippled, or retired. No information was collected on each patient's job or position. Many patients may have changed to an easier job to maintain with this disease; therefore, physically demanding jobs may be under-represented. Our study also did not differentiate between part-time and full-time work, which may have affected the results.

Despite these limitations, this study presents important findings for treatment of patients with RA. Patients receiving adalimumab were able to continue working longer and showed greater clinical/functional status improvement than did those receiving DMARDs. The ability to continue working translates directly into economic outcomes. The average monthly wages in Norway (for all salaried employees) was NOK29200 in $2005 .{ }^{59}$ This corresponds to approximately $€ 3589 .{ }^{60}$ Thus, the additional time worked among adalimumab patients corresponds to more than $€ 7179$ in earnings per patient over the 2-year study period. For those patients who were working at baseline, the difference in time worked (0.61 years) corresponds to increased earnings of more than $€ 26000$ for adalimumab patients. Thus, adalimumab treatment may not only improve clinical status but 
also increase the household earnings of individuals receiving this treatment and reduce the social support to compensate for these lost earnings. On both individual and societal levels, the ability to continue working is a factor of major economic and quality-of-life importance for patients with RA.

Acknowledgements: The authors acknowledge the editorial support of $L$ Lush, JK Associates, in the preparation of this manuscript.

Funding: Abbott Laboratories sponsored the trial and was responsible for data collection and analysis. The authors and the sponsor designed the present study, interpreted the data, prepared the manuscript, and decided to publish.

Competing interests: $\mathrm{MH}$ : I declare that I participated in the study as an investigator and was involved in the evaluation of the data and writing of the manuscript. I have received research grants from Abbott Laboratories; MC: I declare that I participated in the study and manuscript development and that I have seen and approved the final version. I have the following conflicts of interest: hold stock option and employed by Abbott Laboratories; TKK: I declare that I participated in study as an investigator and I have seen and approved the final version. I have received research grants and consulting fees from Abbott Laboratories as well as all other pharmaceutical companies marketing biological agents for use in rheumatoid arthritis.

Ethics approval: Ethics committees at each study site approved the protocol for the DE033 study.

Patient consent: Obtained.

\section{REFERENCES}

1. Hanova P, Pavelka K, Dostal C, Holcatova I, Pikhart H. Epidemiology of rheumatoid arthritis, juvenile idiopathic arthritis and gout in two regions of the Czech Republic in a descriptive population-based survey in 2002-2003. Clin Exp Rheumatol 2006:24:499-507.

2. Silman AJ, Pearson JE. Epidemiology and genetics of rheumatoid arthritis. Arthritis Res 2002;4(Suppl 3):S265-72.

3. Symmons D, Turner G, Webb R, Asten P, Barrett E, Lunt M, et al. The prevalence of rheumatoid arthritis in the United Kingdom: new estimates for a new century. Rheumatology (Oxford) 2002;41:793-800.

4. Yelin E, Callahan LF, for the National Arthritis Data Work Group. The economic cost and social psychological impact of musculoskeletal conditions. Arthritis Rheum 1995;38:1351-6.

5. Choi HK, Hernan MA, Seeger SD, Robins JM, Wolfe F. Methotrexate and mortality in patients with rheumatoid arthritis: a prospective study. Lancet 2002:359:1173-7.

6. Maetzel A, Tugwell P, Boers M, Guillemin F, Coyle D, Drummond M, et al. Economic evaluation of programs or interventions in the management of rheumatoid arthritis: defining a consensus-based reference case. J Rheumatol 2003;30:891-6.

7. Pincus T, Callahan LF. The 'side effects' of rheumatoid arthritis: joint destruction, disability, and early mortality. Br J Rheumatol 1993;32(Suppl 1):28-37.

8. Wolfe F, Michaud K, Gefeller 0, Choi HK. Predicting mortality in patients with rheumatoid arthritis. Arthritis Rheum 2003;48:1530-42.

9. Wong JB, Ramey DR, Singh G. Long-term morbidity, mortality and economics of rheumatoid arthritis. Arthritis Rheum 2001:44:2746-9.

10. Kobelt G, Eberhardt K, Jönsson L, Jönsson B. Economic consequences of the progression of rheumatoid arthritis in Sweden. Arthritis Rheum 1999:42:347-56.

11. Leardini G, Salaffi F, Montanelli R, Gerzeli S, Canesi B. A multicenter cost-of-illness study on rheumatoid arthritis in Italy. Clin Exp Rheumatol 2002;20:505-5.

12. Yelin E. The costs of rheumatoid arthritis: absolute, incremental and marginal estimates. J Rheumatol 1996;23(Suppl 44):47-51.

13. Jonsson D, Husberg M. Socioeconomic costs of rheumatic diseases. Implications for technology assessment. Int J Technol Assess Health Care 2000;16:1193-200.

14. Schmidt A, Husberg M, Bernfort L. Socioeconomic costs for rheumatic disease. CMT Rapport 2003:5. Linköping: Centre for Medical Technology Assessment, Linköping University, Sweden [in Swedish].

15. Hallert E, Husberg M, Jonsson D, Skogh T. Rheumatoid arthritis is already expensive during the first year of the disease (the Swedish TIRA project). Rheumatology (Oxford) 2004;43:1374-82.

16. Hallert E, Husberg M, Skogh T. Costs and course of disease and function in early rheumatoid arthritis: a 3-year follow-up (the Swedish TIRA project). Rheumatology (Oxford) 2006;45:325-31.

17. Clarke AE, Levinton C, Joseph L, Penrod J, Zowall H, Sibley JT, et al. Predicting the short term direct medical costs incurred by patients with rheumatoid arthritis. J Rheumatol 1999;26:1068-75.

18. Lubeck DP, Spitz PW, Fries JF, Wolfe F, Mitchell DM, Roth SH. A multicenter study of annual health service utilization and costs in rheumatoid arthritis. Arthritis Rheum 1986;29:488-93.

19. Merkesdal S, Ruof J, Schoffski O, Bernitt K, Zeidler H, Mau W. Indirect medical costs in early rheumatoid arthritis: composition of and changes in indirect costs within the first three years of disease. Arthritis Rheum 2001:44:528-34.

20. Yelin E, Wanke LA. An assessment of the annual and long-term direct costs of rheumatoid arthritis: the impact of poor function and functional decline. Arthritis Rheum 1999:42:1209-18.
21. Odegard S, Finset A, Kvien TK, Mowinckel P, Uhlig T. Work disability in rheumatoid arthritis is predicted by physical and psychological health status: a 7-year study from the Oslo RA register. Scand J Rheumatol 2005;34:441-7.

22. Li X, Gignac MA, Anis AH. The indirect costs of arthritis resulting from unemployment, reduced performance, and occupational changes while at work. Med Care 2006;44:304-10.

23. Kavanaugh A, Han C, Bala M. Functional status and radiographic joint damage are associated with health economic outcomes in patients with rheumatoid arthritis. J Rheumatol 2004;31:849-55.

24. Kremer JM. Rational use of new and existing disease-modifying agents in rheumatoid arthritis. Ann Intern Med 2001;138:695-706.

25. Bresnihan B, Alvaro-Gracia JM, Cobby M, Doherty M, Domljan Z, Emery P, et al. Treatment of rheumatoid arthritis with recombinant human interleukin-1 receptor antagonist. Arthritis Rheum 1998;41:2196-204

26. Maini R, St. Clair EW, Breedveld F, Furst D, Kalden J, Weisman M, et al. Infliximab (chimeric anti-tumour necrosis factor alpha monoclonal antibody) versus placebo in rheumatoid arthritis patients receiving concomitant methotrexate: a randomised phase III trial. ATTRACT Study Group. Lancet 1999;354:932-9.

27. Moreland LW, Baumgartner SW, Schiff MH, Tindall EA, Fleischmann RM, Weaver $\mathrm{AL}$, et al. Treatment of rheumatoid arthritis with a recombinant human tumor necrosis factor receptor (p75)-Fc fusion protein. N Engl J Med 1997;337:141-7.

28. Weinblatt ME, Keystone EC, Furst DE, Moreland LW, Weisman MH, Birbara CA, et al. Adalimumab, a fully human anti-tumor necrosis factor alpha monoclonal antibody, for the treatment of rheumatoid arthritis in patients taking concomitant methotrexate: the ARMADA trial. Arthritis Rheum 2003;48:35-45.

29. Burton W, Morrison A, Maclean R, Ruderman E. Systematic review of studies of productivity loss due to rheumatoid arthritis. Occup Med (Lond) 2006;56:18-27.

30. Yelin E, Trupin L, Katz P, Lubeck D, Rush S, Wanke L. Association between etanercept use and employment outcomes among patients with rheumatoid arthritis. Arthritis Rheum 2003;48:3046-54.

31. Mittendorf T, Dietz BM, von der Schulenburg JM, Benter U, Cifaldi M, Sterz R. Adalimumab-treated patients with long-standing rheumatoid arthritis (RA) decrease their resource utilization during the course of long-term treatment. Rheumatology 2007:46(Suppl 1):i103.

32. den Broeder AA, van de Putte LBA, Rau R, Schattenkirchner M, van Riel P, Sander 0 , et al. A single dose, placebo controlled study of the fully human anti-tumor necrosis factor- $\alpha$ antibody adalimumab (D2E7) in patients with rheumatoid arthritis. $J$ Rheumatol 2002:29:2288-98.

33. Rau R, Sander 0 , den Broeder A, Van Riel P, van der Putte L, Kruger K, et al. Long term efficacy and tolerability of multiple IV doses of the fully human anti-TNF antibody D2E7 in patients with rheumatoid arthritis [abstract]. Arthritis Rheum 1998:41(Suppl):S55 (abstract 137).

34. Schattenkirchner M, Kruger K, Sander 0, Rau R, Kroot E-J, van Riel PLCM, et al. Efficacy and tolerability of weekly subcutaneous injections of the fully human antiTNF-antibody D2E7 in patients with rheumatoid arthritis - results of a Phase I study. Arthritis Rheum 1998; $\mathbf{4 1}$ (Suppl):S57

35. van de Putte LBA, Rau R, Breedveld FC, Kalden JR, Malaise MG, van Riel PLCM, et al. Efficacy and safety of the fully human anti-tumour necrosis factor monoclonal antibody adalimumab (D2E7) in DMARD refractory patients with rheumatoid arthritis: a 12 week, phase II study.Ann Rheum Dis 2003;62:1168-77.

36. Rau R, Simianer S, van Riel PLCM, van de Putte LBA, Krüger K, Schattenkirchner M, et al. Rapid alleviation of signs and symptoms of rheumatoid arthritis with intravenous or subcutaneous administration of adalimumab in combination with methotrexate. Scand J Rheumatol 2004;33:145-53.

37. van de Putte LBA, Atkins C, Malaise M, Sany J, Russell AS, van Riel PLCM, et al. Efficacy and safety of adalimumab as monotherapy in patients with rheumatoid arthritis for whom previous disease modifying antirheumatic drug treatment has failed.Ann Rheum Dis 2004;63:508-16.

38. Kvien TK, Heiberg MS, Lie E, Mikkelsen K, Nordvåg BY, Rødevand E. A Norwegian DMARD register: Prescriptions of DMARDs and biological agents to patients with inflammatory rheumatic diseases. Clin Exp Rheumatol 2005:23(Suppl 39):188-94.

39. Arnett FC, Edworthy SM, Bloch DA, McShane DJ, Fries JF, Cooper NS, et al. The American Rheumatism Association 1987 revised criteria for the classification of rheumatoid arthritis. Arthritis Rheum 1988;31:315-24.

40. van Gestel AM, Prevoo MLL, Van't Hof MA, Van Rijswijk MH, Van de Putte LBA, van Riel PL. Development and validation of the European League Against Rheumatism response criteria for rheumatoid arthritis. Arthritis Rheum 1996;39:34-40.

41. van Gestel AM, van Riel PL. Evaluation of early rheumatoid arthritis disease activity and outcome. Baillieres Clin Rheumatol 1997:11:49-63.

42. Valesini G, lannuccelli C, Marocchi E, Pascoli L, Scalzi V, Di Franco M. Biological and clinical effects of anti-TNF alpha treatment. Autoimmun Rev 2007; 7:35-41.

43. Wong M, Ziring D, Korin Y, Desai S, Kim S, Lin J, et al. TNF alpha blockade in human diseases: mechanisms and future directions. Clin Immunol 2008;126:121-36.

44. Haraoui B. The anti-tumor necrosis factor agents are a major advance in the treatment of rheumatoid arthritis. J Rheumatol Supp/ 2005;72:46-7.

45. Voulgari PV, Drosos AA. Adalimumab for rheumatoid arthritis. Expert Opin Biol Ther 2006:6:1349-60.

46. Odegard S, Landewé R, van der Heijde D, Kvien TK, Mowinckel P, Uhlig T. Association of early radiographic damage with impaired physical function in rheumatoid arthritis: a ten-year, longitudinal observational study in 238 patients. Arthritis Rheum 2006;54:68-75

47. van Vollenhoven RF, Ray S, Bojke C, Cifaldi MA, Weisman M. Impact of adalimumab (HUMIRA $\left.{ }^{\circledR}\right)$ combination therapy on expected resource use by patients 
with early rheumatoid arthritis: results from a companion study to PREMIER [abstract]. Ann Rheum Dis 2008;67(Suppl II):650 (abstract AB1079).

48. Chant C, Wilson G, Friedrich JO. Validation of an insulin infusion nomogram for intensive glucose control in critically ill patients. Pharmacotherapy 2005;25:352-9.

49. Fisher DA, Trimble S, Clapp B, Dorsett K. Effect of a patient management system on outcomes of total hip and knee arthroplasty. Clin Orthop Relat Res 1997;345:155-60.

50. Ingle GR, Moudgil A, Vo A, Jordan SC. Cyclosporine-sparing effects of daclizumab in renal allograft recipients. Am J Health-System Pharm 2005;62:391-6.

51. Tegtmeyer FK, Moller J, Richter A, Wilken B, Fischer T. Plasma concentration of elastase-alpha 1-proteinase inhibitor complex in surfactant-treated preterm neonates with respiratory distress syndrome. Eur Respir J 1994;7:260-4.

52. Wolfe F, Michaud K. Towards an epidemiology of rheumatoid arthritis outcome with respect to treatment: randomized controlled trials overestimate treatment response and effectiveness. Rheumatology (Oxford) 2005;44(Suppl 4):iv18-iv22.

53. van der Heijde D, Han C, DeVlam K, Burmester G, van den Bosch F, Williamson P, et al. Infliximab improves productivity and reduces workday loss in patients with ankylosing spondylitis: results from a randomized, placebo-controlled trial. Arthritis Rheum 2006;55:569-74.
54. Smolen JS, Han C, van der Heijde D, Emery P, Bathon JM, Keystone E, et al. Infliximab treatment maintains employability in patients with early rheumatoid arthritis. Arthritis Rheum 2006;54:716-22.

55. Puolakka K, Kautiainen $\mathrm{H}$, Mottonen $\mathrm{T}$, Hannonen $\mathrm{P}$, Korpela $\mathrm{M}$, Julkunen $\mathrm{H}$, et al. Impact of initial aggressive drug treatment with a combination of disease-modifying antirheumatic drugs on the development of work disability in early rheumatoid arthritis: a five-year randomized followup trial. Arthritis Rheum 2004;50:55-62.

56. Puolakka K, Kautiainen H, Mottonen T, Hannonen P, Hakala M, Korpela M, et al. Predictors of productivity loss in early rheumatoid arthritis: a 5-year follow-up study. Ann Rheum Dis 2005:64:130-3.

57. Chung DP, Sokka T, Arbogast PG, Pincus T. Work disability in early rheumatoid arthritis: higher rates but better clinical status in Finland compared with the US. Ann Rheum Dis 2006;65:1653-7.

58. Zandbelt MM, Houbiers JG, van den Hoogen FH, Meijerink J, van Riel PL, in't Hout J, et al. Intranasal administration of recombinant human cartilage glycoprotein-39. A phase I escalating cohort study in patients with rheumatoid arthritis. J Rheumatol 2006;33:1726-33.

59. Statistics Norway. Focus on wages. http://www.ssb.no/english/subjects/06/ lonn_en/ (accessed 18 Dec 2006).

60. Universal Currency Converter. http://www.oanda.com (accessed 18 Dec 2006)

\section{Save your favourite articles and useful searches}

Use the "My folders" feature to save and organise articles you want to return to quickly — saving space on your hard drive. You can also save searches, which will save you time. You will only need to register once for this service, which can be used for this journal or all BMJ Journals, including the BMJ. 